Archivum, LXX (II), 2020, pp. 59-81

\title{
Hoja de servicios y futuro de la sociolingüística catalana: una exploración epistemológica (y glotopolítica)
}

\author{
HeNri Boyer \\ Université Paul-Valéry Montpellier 3 \\ (LABoratoIre DIPRALANG) \\ henri.boyer@univ-montp3.fr
}

Recibido: 07/07/2020

Aceptado: 27/10/2020

\section{RESUMEN:}

Este texto pretende ser una exploración de la historia reciente de la sociolingüística en Cataluña desde su constitución como grupo en los años 70 y de su impacto glotopolitico hasta las controversias actuales frente a la perspectiva independentista.

De tipo claramente nacionalista en sus inicios, fue más que una simple ciencia social: la inspiradora de la reconquista sociolingüistica post-franquista a través de sus recomendaciones y de sus acciones que el poder autónomo de Cataluña ha sabido tener en cuenta.

Actualmente parece desgarrarse en lo que se refiere al diagnóstico sociolingüístico y al objetivo glotopolítico entre una opción que permanece firme en cuanto a las bases originales: el catalán es la única lengua nacional de Catalunya y debe tener, por lo tanto, exclusividad en una eventual República catalana; y otra opción que considera que el bilingüismo catalán-castellano tiene toda su razón de ser en una Cataluña independiente.

PALABRAS CLAVE: Sociolingüística, Conflicto, Normalización, Nacionalismo lingüístico 


\title{
Service sheet and future of Catalan sociolinguistics: an epistemological exploration (... and glotopolitics)
}

\begin{abstract}
:
This text is intended to be an exploration of the recent history of sociolinguistics in Catalonia, from its establishment as a group in the 70 s and its glotopolitic impact, to the current controversies over the independence perspective. Of a distinctly nationalistic type in its beginnings, it was more than just a social science: it consisted of the inspiring force of the post-Franco sociolinguistic reconquest, through its recommendations and its actions that the autonomous power of Catalonia has been able to take into account. It now seems to be torn apart with regard to sociolinguistic diagnosis and the glotopolitic objective, between an option that remains firm in terms of the original bases, i.e., Catalan is the only national language of Catalonia and must, therefore, be exclusive in an eventual Catalan Republic; and a second option that considers that Catalan-Spanish bilingualism has its full raison d'etre in an independent Catalonia.
\end{abstract}

KEYWORDS: Sociolinguistics, Conflict, Standardization, Linguistic Nationalism

La principal singularidad de la sociolingüística catalana (a partir de ahora SC) (esencialmente de Cataluña -el Principat- y del País Valenciano) es sin duda la identidad de sus padres fundadores. La historia parece haber retenido cuatro personalidades (Leprêtre y Bañeres, 2002), dos valencianos (Ll. V. Aracil y R. Ll. Ninyoles) y dos barceloneses (A. Badia i Margarit y F. Vallverdú), que sentaron las bases (con otros menos conocidos) de un Colectivo: el Grup Català de Sociolingüística (1973) cuya primera manifestación científica importante fue seguramente la participación oficial en el VIII Congreso Mundial de Sociología celebrado en Toronto en 1974.

El Grupo (cuyos miembros han aumentado considerablemente a lo largo de los años) tomó en 2005 el nombre de Associació de Sociolingüistes de Llengua Catalana y luego en 2008, bajo tutela del Institut d'Estudis Catalans, pasó a llamarse Societat Catalana de Sociolingüística (SOCS).

Es decir, la autopercepción de ser, si no una «escuela», al menos un colectivo perfectamente identificable, y de considerarse 
un interlocutor esencial del movimiento asociativo y de las autoridades públicas en términos de gestión glotopolítica en el ámbito catalán, ha estado presente desde el principio. Tanto es así que podemos decir que la mayor parte de la tradición sociolingüística catalana coincide con la historia de este colectivo (Pradilla Cardona, 2011). Cabe señalar que a pesar de que la aportación (estrictamente teórica) de los fundadores de origen valenciano fue sin duda decisiva, es en el Principat y especialmente en Barcelona donde prosperó la notoriedad del Colectivo y donde su impacto sociopolítico fue más evidente.

Otra singularidad de la SC se debe al enraizamiento de los fundadores en la sociedad civil, a su implicación en el movimiento social y al hecho de que para ellos la sociolingüística es un arma al servicio de la defensa y promoción de una identidad colectiva amenazada, y para decirlo sin rodeos, de una nación amenazada. Badia insistió en el VIII Congreso Mundial de Sociología de Toronto sobre «la tarea inevitable», sobre la «tarea fundamental» de la sociolingüística catalana impuesta por el «contacto [del catalán] con la «otra lengua» (Badia, 1977: 26) ${ }^{1}$. Y el propio Badia citaba a Aracil: «Sin duda, el significado y la fuerza de la sociolingüística catalana [...] pueden explicarse por el hecho de que nuestro trabajo científico es parte de un gran movimiento histórico» (Badia, 1977: 20).

En las siguientes líneas insistiré sobre las singularidades mencionadas, al proponer una identificación inevitablemente ecléctica, a lo largo de la historia de este colectivo, sus fundamentos y su articulación con el proceso de transformación de la sociedad catalana en la España post-franquista y especialmente de la configuración lingüística heredada de la dictadura, indicando algunos elementos de la dinámica del dominio catalán, esencialmente con respecto al Principat, y especialmente durante $\mathrm{el}$ «procès independentista».

1 Todas las traducciones del catalán en este artículo son del autor. 


\section{Fundamentos}

El marco teórico y metodológico catalán para tratar situaciones de diglosia elaborado por la SC constituye una ruptura, al mismo tiempo que una especie de retorno a los orígenes ${ }^{2}$. De hecho, los padres fundadores: LV Aracil, RL Ninyoles, A. Badia i Margarit, F. Vallverdú, ofrecen un análisis en profundidad de la configuración sociolingüística vivida en su propia comunidad, un análisis que toma plenamente en cuenta las ideologías, representaciones, actitudes y los prejuicios (por ejemplo: Ninyoles 1971 y 1976, Aracil, 1982 [1966]) que forman parte de una configuración lingüística dada. La SC considera que, si hay un contacto desigual de dos idiomas en el mismo espacio social, hay necesariamente competencia e inevitablemente conflicto. Esta modelización nace del análisis de situaciones concretas experimentadas en territorios de habla catalana (particularmente en el país valenciano).

Por lo tanto, la SC desde su aparición se presenta como una sociolingüística crítica (Boyer, 1991) que adopta precisamente de manera crítica el modelo sociolingüístico norteamericano (en particular sobre la «diglosia» (Vallverdú, 1980b): los catalanes en España viven una situación de dominación (con manifestaciones variables según el ámbito geolingüístico). Por lo tanto, la diglosia analizada no es equilibrada ni estable: su fuerza motriz es el conflicto: entre un idioma dominante y un idioma dominado. La política del Estado español en el País Valenciano y en Cataluña ha llevado a una minoración, a una marginación del catalán. Los sociolingüistas catalano-valencianos denuncian la gestión franquista de las lenguas de España que privilegia el castellano, y entran en resistencia contra el objetivo de sustitución lingüística: quieren ser los instigadores de una reconquista sociolingüística colectiva; la implicación del sociolingüista es el credo de la SC emergente (Badia i Margarit, 1977).

Francesc Vallverdú, citando a A. M. Badia i Margarit, para quien «la sociolingüística catalana se siente comprometida con

2 En cuanto a la epistemología del concepto de «diglosia» del que es creador el helenista Jean Psichari, véase, por ejemplo, Kremnitz, 1981, Jardel, 1982, Boyer, 1986. 
la gente y, por su parte, el pueblo catalán apoya la sociolingüística» (Badia i Margarit, 1976, citado por Vallverdú, 1980: 639), considera que lo que está en juego no es ni más ni menos la «vieja cuestión de la neutralidad científica» (Vallverdú, 1980: 639). Y no duda en convocar a la sociolingüística norteamericana para observar que el interés de los investigadores sociolingüistas por los problemas de la población negra y de otras minorías no es neutral. No es casualidad que parte de las investigaciones en cuestión hayan sido financiadas institucionalmente. Y, por lo tanto, no es sorprendente observar que «los objetivos de la sociolingüística se adaptan de manera tan diferente a los intereses de los diferentes países» (Vallverdú, 1980: 640). Sin embargo, Vallverdú enfatiza esta peculiaridad de la sociolingüística catalana: es una sociolingüística que «desde sus orígenes está marcada por [el] carácter contra-institucional». Esta posición, digamos contestataria, «comprometida con el pueblo» según los términos de Badia, condiciona obviamente la investigación de nuestros sociolingüistas «(Ibid., 641). Esto significa que para este destacado observador-actor la implicación de la SC coincide con su carácter contra-institucional ${ }^{3}$.

Para Ll. V. Aracil, los discursos legitimados a favor del bilingüismo social son engañosos porque disimulan la situación de conflicto: cuando se trata del poder de un idioma sobre otro, el bilingüismo es inevitablemente desigual y es probablemente el vestíbulo de un monolingüismo a favor del único idioma dominante. Por lo tanto, si hay una polarización diglósica, hay necesariamente un conflicto (Aracil, 1965 y 1982, Ninyoles, 1969) y si hay un conflicto hay un dilema: o el idioma dominante prosigue su dominación y en este caso reemplazará de manera más o menos lenta pero segura la lengua dominada o de lo contrario la comunidad que usa la lengua dominada resistirá la dinámica de

3 Pero Vallverdú ya sospechaba con razón, en esos años del comienzo de la reconquista, la «institucionalización» cercana de la sociolingüística que la política lingüística de la Generalidad restaurada tendió probablemente a operar desde mediados de los años ochenta. 
subordinación y sustitución y luchará (a través de la acción colectiva de los usuarios pero posiblemente gracias a una intervención institucional) por un desarrollo normal de los usos sociales de la lengua dominada. Se trata de promover la normalización, un concepto clave del edificio teórico en construcción (Aracil, 1965). Se puede decir que esta es una contribución esencial en el campo de la sociolingüística aplicada: la acción de política lingüística. Para Aracil, la normalización "consiste sobre todo en el desarrollo e implementación de sistemas de normas para el uso lingüístico. Sin embargo, esto supone necesariamente que la normalización siempre es consciente. En realidad, siempre que sea prospectiva por definición, también es previsora. Implica, de hecho, no solo una actitud favorable hacia la lengua a normalizar, sino también [...] esperanza y confianza en la efectividad de la acción social [...] Una verdadera normalización nunca puede limitarse a los aspectos "meramente" lingüísticos. Al mismo tiempo, debe considerar muchos factores decididamente «sociales», incluso esencialmente políticos « (Aracil, 1982: 9).

Sin embargo, para que el idioma dominado se normalice, para que sea un idioma de pleno ejercicio, primero debe normativizarse, es decir que los miembros de la comunidad hayan aceptado la elección de un estándar, una codificación, que permitan que este idioma se escriba, se enseñe y se use en todos los ámbitos de la vida pública (administración, medios de comunicación, etc.). Para la SC, sin normativización no hay normalización posible.

Una de las principales contribuciones de este modelo es haber insistido en la importancia de las ideologías, representaciones... Es el caso de la actitud llamada por R. Ll Ninyoles «autoodi» (Alén Garabato y Colonna dir., 2016), provocado por una ideología diglósica y, por lo tanto, por representaciones estigmatizantes de la lengua dominada que consisten en hacer que los dominados acepten la idea de que su lengua es inferior, que no tiene ninguna utilidad social, que debe ser abandonada: para dejar de ser un ciudadano de segunda clase, uno debe hablar el idioma dominante. L. V. Aracil denuncia el «mito bilingüista» porque 
el bilingüismo desigual de hoy anuncia el monolingüismo del mañana. (Aracil, 1982 [1966]).

\section{Cuestión de territorio}

Más allá de la diversidad de las posiciones identitarias-nacionalistas y de los proyectos con respecto al desarrollo deseable del estado español, la cuestión del espacio geolingüístico identificado como nacional se plantea desde hace largo tiempo en el dominio catalán. Y como se ha podido observar en otros nacionalismos lingüísticos (Boyer, 2008), debemos hablar de pan-catalanismo a propósito de la pretensión de una importante tendencia del nacionalismo lingüístico catalán, a extenderse, bajo la denominación de «Països Catalans», la nación catalana que incluye todos los territorios históricamente de habla catalana, donde, sin embargo, el uso social del catalán es hoy de importancia muy variable: además del «Principat», las Islas Baleares, el País Valenciano, el Rosellón, Andorra, la Franja Oriental de Aragón y la ciudad sarda de Alguer.

Y hay que señalar que los sociolingüistas (que en su mayor parte han desempeñado y continúan desempeñando un papel de liderazgo en la construcción y consolidación del nacionalismo catalán) generalmente identifican (como lo hacen otros mi-

4 Este expansionismo obviamente no es unánimemente aceptado, especialmente en algunos de los territorios involucrados. Se pueden observar fenómenos de rechazo, en particular en forma de conflictos glosonímicos, como en la Comunidad Valenciana, donde «valenciano» («valencià») se opone a «catalán» («català»). Aunque es, estrictamente hablando desde un punto de vista lingüístico, el mismo idioma, es el nombre de «valenciano» el que fue elegido para designar oficialmente el idioma apropiado de la Comunidad (ver Martin, en Boyer y Lagarde, dir., 2002: 123-126). En la Comunidad de las Islas Baleares incluso se podía observar la aparición de un micronacionalismo lingüístico (muy minoritario), rechazando la denominación, oficial en esta Comunidad, de «catalán» a favor de «lengua balear» («sa llengo balear «) (Sintas, 2000). Es el caso también de la polémica entono al LAPAO (catalán de la Franja de Aragón), más recientemente (Alén Garabato, 2016). Por otra parte, este tropismo geolingüístico pan-catalanista no es unánime ni siquiera en Cataluña. Algunos sociolingüistas prefieren hablar de «catalanofonía» en lugar de «Països Catalans» (véase, por ejemplo, Pradilla, 2015). 
litantes nacionalistas) la nación catalana con los «Països Catalanes» (véase, por ejemplo, Pradilla ed., 1999). Este es el caso, por ejemplo, de Modest Prats, un académico, especialista en historia de la lengua catalana, que declaró en Las Segundas Jornadas dedicadas al nacionalismo catalán a finales del siglo XX: «Nosotros sabemos que la conexión entre la lengua catalana y la nación catalana (está claro que estoy pensando en los Países Catalanes) es un elemento esencial de nuestro proyecto [nacionalista] «(Prats 1989: 89, la cursiva es mía). Durante las mismas Jornadas, Aina Moll (también sociolingüista que ocupó una posición central en materia de política lingüística a favor del catalán, primero como primera Directora General de Política Lingüística dentro del gobierno de Cataluña, luego como Directora de la Campaña de Normalización Lingüística en las Islas Baleares) expresó un posicionamiento similar: después de haber recordado que «la principal característica distintiva de la nación catalana es el idioma» (para ella uno de los principales elementos de consenso dentro del nacionalismo catalán) (Moll, 1989: 99), añadió que España es «un Estado plurinacional, en el que la nación catalana está formada por Comunidades Autónomas que deben establecer entre ellas los vínculos necesarios para salvaguardar el patrimonio cultural que les es común» (Moll, 1989: 101).

\section{El impacto}

Cataluña (el Principat), más que cualquier otro territorio de habla catalana, ofrece un ejemplo especialmente interesante de articulación entre una teoría sociolingüística desarrollada en relación con una resistencia colectiva y la realización oficial de una política lingüística (Boyer, 1987). Esta Comunidad Autónoma no es solo, desde principios de los años ochenta, la locomotora de las reconquistas sociolingüísticas para las lenguas de España distintas del castellano (euskera, gallego), se ha convertido además en un modelo en materia glotopolítica a nivel internacional. En su confrontación de tres de las acciones contemporáneas de inversión de una sustitución lingüística, J.-A. Fishman (1993), al mismo tiem- 
po que considera que el objetivo de una completa normalización necesitará más tiempo que en el caso del hebreo en Israel o del francés en Quebec, elogia la restauración en Cataluña del catalán como lengua de comunicación de pleno ejercicio de una sociedad moderna, tanto funcional como simbólicamente; una restauración por otra parte consensual (Fishman, 1993). Este reconocimiento es compartido por gran parte de la comunidad científica de los sociolingüistas que evalúan en su justa medida la distancia recorrida en el Principat en dos décadas de normalización lingüística oficial.

Y es importante subrayar que la normalización lingüística en el Principat se ha desarrollado de acuerdo con los dos ejes solidarios de cualquier «mercado lingüístico» (Bourdieu, 1982): el de los usos y el de las representaciones, haciendo todo lo posible institucionalmente (por parte del Gobierno Autónomo) para que el dispositivo (las estructuras apropiadas) y las disposiciones (legislativas, reglamentarias) estén a la altura del desafío, teniendo en cuenta la situación heredada, en gran medida desfavorable para la lengua catalana. El dispositivo central (la Dirección General de Política Lingüística y luego la Secretaría de Política Lingüística) se vio reforzado por el establecimiento de otras instituciones y otros servicios adecuados para articular aún mejor los objetivos glotopolíticos del Gobierno Autónomo y las realidades del terreno (del municipio, del barrio, de la empresa, del sindicato...) La noción de normalización que, como hemos visto, surgió de la modelización teórica construida in situ por la SC fue asumida oficialmente por la Generalitat como un objetivo político. Ciertamente, ni las instituciones específicas creadas para implementar la política lingüística, ni la «Ley de normalización» votada por el Parlamento catalán en 1983, garantizaban el futuro del «lengua propia» de Cataluña. Sin embargo, se puede considerar que la desestabilización de la polaridad diglósica heredada del franquismo ha sido efectiva. Y la inversión de legitimidad en el mercado lingüístico ha producido además a lo largo de un proceso iniciado a principios de los años ochenta varias reacciones de hostilidad siempre minoritarias. 


\section{Un interdiscurso epilingüístico recurrente}

La vida político-mediática catalana se interesa regularmente por la cuestión lingüística. P. Pujades (1988) habla de «batalla de la lengua»; para E. Voltas (1996) se trata de una «guerra de la lengua» en un trabajo en el que presenta una acusación documentada contra las oposiciones a esta o a aquella fase de la normalización lingüística a favor del catalán dirigida por el gobierno autónomo, particularmente entre 1993 y 1996, a propósito de la implementación generalizada de la estrategia pedagógica de inmersión lingüística ${ }^{5}$ en las escuelas catalanas. Las controversias sobre el / los idioma (s) en uso en Cataluña (catalán, castellano), que de hecho solo conciernen a una minoría de actores pero cuyo impacto, a través de medios interpuestos, en el estado del imaginario colectivo está lejos de ser insignificante, son un fermento importante en el proceso constante de proclamación de la identidad nacional en torno a la única «lengua propia ", el catalán, con punta de lanza de la SC (Boyer 1991: 233-237; Boyer y Lagarde dir., 2002).

Así, en lo que concierne a la mayor parte del período post-franquista, podemos suscribirnos al punto de vista de $\mathrm{T}$. Cabré y C. Lleal, quienes, después de recordar que «el idioma es en Cataluña un elemento fundamental del nacionalismo, $[\ldots]$ sin duda el elemento más significativo de identificación «, observan, a través de una lectura de las primeras polémicas de contenido epilingüístico a las que he aludido, que» la defensa de la lengua catalana, cuando es atacada por grupos anti-catalanes, homogeneiza la diversidad ideológica de los partidos políticos catalanes» porque «en ese momento hay un solo enemigo»(Cabré y Lleal,, 1986: 141-142).

Y en una configuración de salida de la diglosia, donde la normalización lingüística se ha llevado a cabo con firmeza y continuidad, la sociedad y la comunicación social producen

5 Se sabe que la inmersión lingüística es una estrategia para aprender un idioma no nativo que consiste en hacer de este idioma el idioma de instrucción (y no simplemente un idioma enseñado). 
constantemente un interdiscurso epilingüístico prolífico e inevitablemente polémico. Este sigue siendo el caso en la Cataluña autónoma y lo será durante mucho tiempo. Este interdiscurso epilingüístico encuentra en la prensa y las publicaciones catalanas (tanto en catalán como en castellano) y por supuesto en la televisión (TV3, el canal de televisión bajo la autoridad de la Generalitat) una acogida favorable. Participan en este interdiscurso varios tipos de actores sociales (políticos, artistas, académicos, miembros de profesiones liberales, periodistas por supuesto, sindicalistas... por no hablar de los sociolingüistas y otros militantes de la lengua catalana). Es esencialmente un discurso escindido cuyos estímulos glotopolíticos no siempre son de origen interno a Cataluña, sino que también provienen del Centro (del Estado).

Así, en el interdiscurso epilingüístico catalán encontramos esta insistencia en las secuelas del conflicto pasado y en el mantenimiento del dominio en el presente, destacando las resistencias a la normalización oficial, a veces para estimular esta normalización, a veces incluso para denunciar su tibieza. A este respecto, los estudios (encuestas en particular), así como los trabajos con contenido polémico han prosperado a lo largo de los años, sin interrupción, algunos para extender las consideraciones (críticas) a los «Països catalans» (ver, por ejemplo, Querol, 2007, Bernat, 2007), pero otros muchos, circunscritos a la situación del Principat, para denunciar el hecho de que a pesar de las razones para estar satisfechos con los resultados de la normalización, la «lengua propia» no ha neutralizado totalmente en su favor la dinámica de sustitución heredada del franquismo.

Por otra parte, la SC ha sabido acompañar la dinámica de normalización de la situación del catalán adaptándose y diversificándose. Tanto es así que hoy (y desde hace muchos años) es difícil hablar de una sociolingüística catalana

Por un lado, debe señalarse que el proceso de normalización sociolingüística, indiscutiblemente favorable a la extensión de los usos del catalán, tuvo como consecuencia la institucionalización, la «burocratización» en cierta manera, de la sociolingüística 
en Cataluña. La acción militante de los sociolingüistas ha perdido fuerza con la aparición de una «sociolingüística funcionarizada», «dejando [...] de lado la sociolingüística crítica» (Leprêtre y Bañeres, 2002: 121). De hecho, me parece que la dimensión demolingüística ha predominado sobre la dimensión teórica y metodológica, dentro de la producción editorial de naturaleza sociolingüística (ver, por ejemplo, Querol, coord., 2007; para una síntesis, ver Torres i Pla (2011).

En este sentido, un trabajo como el de Emili Boix (Boix-Fuster 1993) es ejemplar. Este autor (entre otros) destaca la aparición de un rasgo de dinámica conversacional entre los jóvenes educados en los dos idiomas oficiales de Cataluña (castellano y catalán): la práctica aleatoria del cambio de lengua. Y al analizar su motivación, además de lo que puede significar para el futuro de la configuración sociolingüística de Barcelona, este académico de «segunda generación» de la SC también ha abierto el camino para un nuevo ciclo científico. El título de su trabajo es, además, implícitamente una toma de posición epistemológica (Triar no és trair, «Elegir no es traicionar»): probablemente la época en la que se afirmaba la identidad al negarse al cambio conversacional de lengua se ha terminado, ya que la generación de los jóvenes ha experimentado circunstancias etnosociolingüísticas diferentes a las de sus mayores. ¿Significa esto que «los esquemas identitarios [están] desactualizados»? Como mínimo, se puede argumentar que «no es razonable [...] persistir en la idea de una identidad de habla catalana impermeable « (Nicolas i Amoros, 2000: 181).

Del mismo modo, si la implicación del sociolingüista sigue siendo una singularidad reivindicada por los sociolingüistas del ámbito catalán, se observan nuevas exigencias, que toman en cuenta las evoluciones sociales y científicas de las últimas décadas, en Cataluña y en España en particular. En lugar de la «ciencia connotada» (afectivamente) reclamada por Badia i Margarit en la década de los setenta (Badia i Margarit, 1976), la sociolingüística en Cataluña puede optar hoy por un posicionamiento 
más sobrio y riguroso, tal como lo expresa E. Boix en el estudio citado:

En nuestro país, la sociolingüística surgió comprometida, hostil a la neutralidad frente al conflicto lingüístico en los Países catalanes, con el deseo de intervenir en los proyectos de recuperación nacional y social. El estudio que presento aquí quiere continuar en esta tradición de intereses en los asuntos colectivos, pero quiero asociarlo con exigencias de rigor. Creo que las emociones y las pasiones son necesarias para arrancar y mantener los motores en funcionamiento, pero que luego uno debe saber dónde están los problemas y tener los datos para poder pronunciarse, tratando de no confundir nuestras descripciones con nuestras esperanzas. (Boix 1993:13; la cursiva es mía).

Esta posición epistemológica (pertinente en mi opinión) sonaba como una advertencia. Sin embargo, no es seguro que su autor hoy comparta plenamente las posiciones de una parte de la SC que, en el contexto de la «crisis catalana» y del debate sobre el futuro del estatus glotopolítico del castellano en la perspectiva del establecimiento de una República catalana, puso en tela de juicio el dogma del «bilingüisme com a mite « del que hablaba Ll V Aracil.

\section{¿La sociolingüística catalana en crisis?}

¿De qué se trata? De un episodio importante que surgió en medio del «proceso independentista catalán» iniciado en julio de 2010, tras la Sentència del Tribunal Constitucional español que socavaba las prerrogativas del catalán dentro del dispositivo de política lingüística previsto por el Estatuto de Autonomía de 2006.

Como se ha señalado, debe reconocerse que el nacionalismo lingüístico (Boyer, 2008) ha tenido un impacto decisivo en la política lingüística llevada a cabo institucionalmente por el poder autónomo en la Comunidad de Cataluña desde 1980, cuando se estableció un dispositivo oficial de normalización del uso del catalán capaz de coordinar esfuerzos a favor de la reconquista de 
los dominios sociolingüísticos perdidos durante el largo proceso de minoración sociolingüística ${ }^{6}$, hasta causar un reequilibrio auténtico de los estatutos y los usos de los dos idiomas presentes (castellano-catalán). Hablar de un impacto decisivo es considerar que, sin la traducción glotopolítica voluntarista del nacionalismo catalán llevada a cabo por la coalición gobernante en Cataluña durante dos décadas ${ }^{7}$, la reconquista de los usos sociolingüísticos del catalán en Cataluña no sería lo que es, como muestran las evaluaciones demolingüísticas ${ }^{8}$.

6 La minoración es un proceso sociolingüístico que lleva a restringir el espacio de comunicación de un idioma hasta el punto de convertirlo en un idioma minoritario, es decir, un idioma menor, porque está separado de muchas de las prerrogativas de una lengua de ejercicio social completo (hasta que esté reservado exclusivamente a la esfera privada, la fase final que anuncia su desaparición total), un proceso que se alimenta de una ideología y, por lo tanto, de representaciones degradantes y discriminatorias.

7 El Parlamento catalán aprobó dos leyes lingüísticas tras la aprobación del primer estatuto de autonomía: la primera en 1983 (conocido como «de normalización lingüística del catalán»), la segunda en 1998 (conocida como «de política lingüística») (Dirección General de Política Lingüística 1983 y Generalitat de Catalunya 1998). Entre estas dos leyes (y sus decretos de implementación), la primera de las cuales tenía el objetivo declarado de «normalización», es decir, hacer de la «lengua propia» de Cataluña un idioma de ejercicio social pleno, ha habido un desarrollo muy significativo en la política lingüística del gobierno autónomo. Con la ley de 1998 se trataba de hacer del catalán la lengua prioritaria de Cataluña. De hecho, la ley de 1998 especifica los estatutos de las dos lenguas cooficiales de Cataluña, de acuerdo con los dos principios de la ley en la materia:

- El catalán es el «idioma propio» de la Comunidad, el único (principio de territorialidad), por lo tanto, debe utilizarse colectivamente como una prioridad.

- El castellano es el idioma del Estado (Mackey, 1976) español, idioma cooficial en Cataluña y todo ciudadano tiene el derecho (principio de personalidad) a comunicarse con las autoridades públicas en este idioma.

8 Uno de los indicadores más esclarecedores del estado de una reconquista sociolingüística (y del impacto de una política lingüística) es seguramente la progresión de la transmisión intergeneracional del idioma que ha sufrido un proceso de subestimación. Sin embargo, en 2013, el 32,6\% de la población de Cataluña declaraba haber hablado catalán con su madre, mientras que el $44 \%$ declaraba hacerlo con sus hijos: así, no solo los catalanohablantes transmiten la lengua, sino que además la transmite también gente que no la utilizaba con su madre (Xarxa CRUSCAT-IEC 2015: 48). 
Solo un año después de la adopción por España de una Constitución democrática, el primer Estatuto de Autonomía de Cataluña (votado en diciembre de 1979) restablece definitivamente la institución secular de la Generalitat en sus poderes legislativo y regulatorio y destaca en su artículo 3 la identidad lingüística: «La lengua propia de Cataluña es el catalán»; es «la lengua oficial de Cataluña»; pero agrega «como es el castellano, idioma oficial en todo el estado español», del que la «Generalidad garantizará el uso normal» (Generalitat de Catalunya 1982).

El deseo de asentar la autonomía, pero también de incluir en un texto que tenga el valor de una Ley Fundamental (para Cataluña) la identidad nacional de Cataluña, condujo, 27 años después del primer Estatuto de autonomía, a la Generalitat (entonces presidida por el socialista Pasqual Maragall), a diseñar un nuevo Estatuto de autonomía, que se promulgó en 2006 (y que define en su Preámbulo Cataluña como una «nación»...).

Este segundo Estatuto de autonomía tuvo su importancia en el estallido de la «crisis» que Cataluña experimentó en la década de 2010. De hecho, el Tribunal Constitucional, a petición del Partido Popular, canceló en junio de 2010 varios artículos de este Estatuto, en particular los relacionados con el estatuto de la lengua catalana (particularmente en el sistema educativo), que de hecho deseaban establecer definitivamente y ampliar las prerrogativas de la Generalitat en materia de política lingüística.

Esta decisión contra un texto que había sido adoptado en su día (2006) por las Cortes de Madrid y por referéndum en Cataluña fue percibida como una nueva agresión por parte del Centro español(ista) contra la nación catalana. El inmediato rechazo de la Sentencia del Tribunal Constitucional, engendró un poderoso movimiento de oposición y afirmación de identidad donde se proclamó claramente la reivindicación soberanista durante una manifestación que reunió a un millón de personas en Barcelona el 10 de julio de 20109 . En mi opinión, la cuestión de la lengua

9 La reivindicación de independencia ya había comenzado a expresarse, en particular a través de referendos organizadas en varios municipios de Cataluña. 
catalana, de su preeminencia en el territorio de la Comunidad Autónoma de Cataluña, fue sin duda alguna el detonante y el principal motor de la «crisis».

\section{La República catalana en el punto de mira ¿qué futuro gloto- político para Cataluña?}

Actualmente, en Cataluña se enfrentan dos supuestos glotopolíticos, que se refieren a la configuración etnosociolingüística de una Cataluña eventualmente independiente (Boyer: 2019):

- uno, monolingüista, reacio al trato social igualitario de las dos lenguas coexistentes ( $\mathrm{y}$ hasta cierto punto aún en conflicto): castellano y catalán.

- el otro que acepta e incluso celebra el bilingüismo (y el plurilingüismo) como una solución equitativa.

El primer posicionamiento fue expuesto por un colectivo a través del Manifiesto del grupo Koiné $(\mathrm{MK})^{10}$. Este manifiesto proclamaba la precedencia de la lengua catalana (y las representaciones de identidad al respecto): es la «lengua endógena del territorio catalán», la «lengua en la que el pueblo catalán siempre ha hablado».

A propósito de la relación problemática entre catalán y castellano en la sociedad catalana, el MK denuncia el «proceso de dominación político-lingüística», la «bilingüización forzada de la población». La conclusión es acusadora: el castellano «disputa coercitivamente [con el catalán] [el] estatuto de lengua territo-

A partir de 2010, la movilización popular no va a detenerse: el 11 de septiembre de 2012, con motivo de la Diada (la fiesta nacional de Cataluña, como dijimos), una espectacular manifestación catalana consiguió reunir a un millón y medio de participantes (según todas las fuentes) en Barcelona con el eslogan omnipresente: “Som una nación. Nosaltres decidim" [Somos una nación. nosotros decidimos].

10 «Manifest del Grup Koiné» (marzo-abril de 2016) a favor de la adopción del monolingüismo catalán con vistas a la eventual creación de una República catalana: «Para una verdadera normalización lingüística en Cataluña independiente" (firmado por 275 lingüistas, sociolingüistas, profesores, escritores, traductores, abogados, etc.). Este manifiesto es, por lo tanto, parte de una amplia controversia dentro del soberanismo catalán, de la cual la prensa obviamente ha sido el principal apoyo (Sendra y Vila, 2016). 
rial». Se habla de «uso subordinado del catalán al castellano»y de «sustitución de la lengua del país por la lengua impuesta por el Estado». Esto lleva a la «degradación estructural del catalán». Una observación no está exenta de controversia: el castellano es el «idioma de la inmigración» (inmigración alentada por el Estado español, particularmente bajo Franco), que usurpa el «papel de idioma del país, de idioma nacional» ... El bilingüismo generalizado de la Comunidad Autónoma, que es un hecho macrosociolingüístico indiscutible (a pesar de la prioridad institucional dada al catalán desde al menos la Ley de Política Lingüística de 1998), se denuncia como resultado de una «ideología política» nociva: «Ideología bilingüista» ${ }^{11}$, que no es otra cosa que el «encubrimiento y [la] legitimación de la subordinación de una lengua [el catalán] a la otra [el castellano] y, por lo tanto, del proceso de sustitución lingüística que sufre la sociedad catalana».

Los objetivos glotopolíticos fijados por el MK, basados en el principio según el cual el problema lingüístico es «quizás el más importante del Estado en la nueva República por construir», son claros: «revertir la práctica de la subordinación sistemática y generalizada del uso del catalán al uso del castellano [creando] un amplio movimiento ciudadano por la normalización lingüística». Se hace un llamamiento a la lealtad lingüística para establecer un monolingüismo institucional.

La difusión del Manifiesto del Grupo Koiné provocó reacciones y, más concretamente, objeciones. El catalanismo no siempre ha sido mayoritariamente independista. Si esta orientación a favor de una República catalana parece haber ganado ventaja en los últimos años, provocada en gran parte por intervenciones hostiles por parte del Estado español, los partidarios y defensores de la «convivència» tradicionalmente celebrada en Cataluña,

11 Aquí encontramos un postulado fundamental para la gran mayoría de los sociolingüistas catalanes: la denuncia del «bilingüismo como mito», es decir, como una falacia porque oscurece la realidad del conflicto y su resultado previsible: la sustitución de la lengua dominada (catalán) por la lengua dominante (castellano) (Aracil 1982: 39-57). 
así como aquellos que son reacios a separarse (mientras permanecen apegados a la lengua y cultura catalanas), incluso si comparten en su mayor parte el diagnóstico histórico de dominación, no consideran el establecimiento de un monolingüismo oficial como la solución correcta. Una de las reacciones críticas más interesantes al MK es sin duda la de un grupo de sociolingüistas reconocidos que, bajo el título de «Precisions al manifest del Grup Koiné», publicaron casi de inmediato una serie de observaciones que van en contra de la ideología lingüística expresada en el MK. Critican este manifiesto por ignorar la «complejidad catalana» que «incluye el carácter bilingüe de sus ciudadanos». La oposición es frontal: para los signatarios de las «Precisions ...» el bilingüismo no es una desventaja sino un «valor añadido». Para ellos, «normalización» no significa necesariamente «monolingüismo». Porque «el bilingüismo no es la causa de la sustitución», incluso si reconocen, como buenos sociolingüistas catalanes, que «el bilingüismo social generalizado es una condición para la sustitución lingüística». También se oponen a la representación reductora de la inmigración de habla hispana en Cataluña: no fue un «instrumento involuntario de colonización lingüística» porque «cientos de miles de personas de lengua castellana [...] participaron activamente en la normalización del catalán». Sin embargo, acuerdan «otorgarle a la lengua catalana en su territorio secular una legitimidad especial». La posición adoptada por este colectivo de sociolingüistas (igualmente catalanistas y soberanistas) expresa el rechazo de una postura fundamentalmente política cara al bilingüismo, optando decididamente por un posicionamiento estrictamente sociolingüístico.

Tampoco se puede ignorar lo que dicen Sendra y Vila (2016) analizando la «mutación ideológica ocurrida dentro del independentismo a finales de la década de 1990 y a principios de la década de 2000» (Ibid., 34): para estos investigadores se habría producido un vuelco de la primacía de la nación a favor del Estado» (Ibid., 35). De ahí la oficialización proyectada del bilingüismo catalán-castellano como un valor social añadido y el elogio de la 
interculturalidad. La hipótesis presentada apuntaría a un declive en la ideología nacionalista (del nacionalismo lingüístico) y, por lo tanto, en la concepción del proceso de independencia como un «proceso de restitución de la soberanía y restauración de la nación» y a cambio de una creciente relevancia del proyecto de «creación de un nuevo país a partir de la población actual» (Ibid., 45). En cierto modo, como si la concepción cívica de la nación tuviera prioridad sobre la concepción cultural-lingüística. Es permisible ver aquí una revisión del paradigma representacional dentro del independentismo que no estaría exento de impacto glotopolítico a medio y largo plazo en Cataluña, independiente o no. Hay motivos para preguntarse si estamos presenciando en Cataluña, si no el final, al menos un cierto declive en el nacionalismo lingüístico, tal como surgió a fines del siglo XIX (durante la Renaixença) y se desarrolló durante el siglo XX, nacido de una reivindicación política y cultural de los catalanes, o un reordenamiento (consentido por realismo sociopolítico o motivado por una disposición sociolingüística legítima a la pluralidad lingüística y al compromiso glotopolítico) de un nacionalismo lingüístico secular. ${ }^{12}$

\section{Referencias bibliográficas}

Alén Garabato, C. (2016) «Langues, variétés et politiques linguistiques : nouveaux conflits en contexte di/pluriglossique en Espagne ", Hétérogénéité et changement : perspectives sociolinguistiques, Cahiers de linguistique ${ }^{\circ} 2016 / 4 / 22$, janvier 2017, sous la direction de Marinette Matthey et Agnès Millet, 79-87.

Alén Garabato, C. et Colonna, R. dir. (2016) L'auto-odi: la «haine de soi» en sociolinguistique, Paris, L'Harmattan.

12 Este artículo se basa en varios trabajos publicados en francés (Boyer 2008, 2012, 2015, 2019, 2020) revisados y reestructurados para su publicación en Archivum. Mi agradecimiento a Carmen Alén Garabato por la apreciable ayuda en la mejora formal de este texto en castellano. Por supuesto, los errores que puedan quedar son de mi incumbencia. 
Aracil, Ll. V. (1965) «Conflit linguistique et normalisation linguistique dans l'Europe nouvelle », Nancy et València ; repris et traduit : "Conflicte lingüístic i normalització lingüística a l’Europa nova ", Papers de sociolingüística, Barcelona, Edicions de la Magrana.

Aracil, Ll. V. (1982 [1966]), «El bilinguisme com a mite», dans Papers de sociolingüística, Barcelona, Edicions de la Magrana.

Aracil, L., V. (1982) Papers de sociolingüística, Barcelona: Edicions de la Magrana.

Badia i Margarit, A.M. (1976) Ciència I pasió dins la linguistic catalane moderna, Barcelona, Universitat de Barcelona (Discurs inaugural des curs académic 1976-77).

BAdia i MARgarit, A.M. (1977) « Entorn de la sociolingüística catalana: precedents, dificultats, contingut, objectius », Treballs de sociolingüística catalana I(1974-1976), Ponèencies al viiiè Congrés Mundial de Sociologia (Toronto), València.

Badia i Margarit, A.M. (1979) « El Grup Català de Sociolingüística i el Seminari Internacional de Sociolingüística de Perpinyà (juliol de 1977), Treballs de sociolingüística catalana, 2 , València.

Bernat, J. (2007) La Nació inconsistent, Barcelona, DUX.

Berrio, A. (2008) Contra el liberalisme i el cofoisme lingüístics, Barcelona, Península.

Boix-Fuster, E. (1993) Triar no és trair. Llengua i identitat en el joves de Barcelona, Barcelona, Edicions 62.

Bourdieu, P. (1982) Ce que parler veut dire, Paris, Fayard.

Bourdieu, P. (1980) «L'identité et la représentation», Paris, Actes de la Recherche en Sciences Sociales, 35, 63-72.

Boyer, H. (2020) «De la «question catalane» à la «crise catalane»», dans Les frontières revisitées, sous la dir. de J-P. Chagnollaud et X. Richet, Paris, L'Harmattan, 2020, 117-143.

Boyer, H. (2019) «Nationalisme linguistique et représentations sociolinguistiques en débat. La sociolinguistique catalane face à la perspective indépendantiste», Cahiers de linguistique $\mathrm{n}^{\circ}$ 45/1, 2019, 93-102. 
Boyer, H. (2015) «Langue et nationalisme: les synergies à l'œuvre dans la neutralisation (relative) du conflit diglossique en Catalogne autonome» dans Discours et effets de sens, sous la dir. de C. Pineira-Tresmontant, Arras, Artois Presses Université, 2015, 139-156.

Boyer, H. (2012) «Singularité(s) de la sociolinguistique du domaine catalan. Un repérage épistémologique», Histoire Epistémologie Langage 34/II, 2012, 29-41.

Boyer, H. (2008) Langue et identité. Sur le nationalisme linguistique, Limoges, Lambert Lucas.

Boyer, H. et Lagarde, Ch., dir. (2002) L'Espagne et ses langues. Un modèle écolinguistique?, Paris, L'Harmattan.

Boyer, H. (1991) Langues en conflit, Paris : L'Harmattan.

Boyer, H. (1992) «Resistencia i reconquesta sociolingüistiques : aspectes de la normalitzacio del català a la Catalunya autonoma», Treballs de sociolingüistica catalana, 10, València, Eliseu Climent, 51-76.

Boyer, H. (1986) «Diglossie : un concept à l'épreuve du terrain ... », Lengas, 20, 21-54.

Boyer, H. (1987) « Sociolinguistique et politique linguistique: l'exemple catalan », Études de Linguistique Appliquée, 65, 69-88.

Cabré Castellvi, M.-T. , Anglada Arboix, E. (1984) «Une polémique sur la situation linguistique en Catalogne », Mots $\mathrm{n}^{\circ} 8$.

Cabré Castellvi, M.-T, Lleal Galieran, C. (1986) «Deux manifestes linguistiques en Calalogne», «Nation» et nationalisme en Espagne du franquisme à la démocratie, Paris, INALF, Klincksieck.

Fishman, J. A. (1993) "Tres casos amb (més o menys) èxit: l'hebreu modern, el francès al Québec I el català a Espanya", Treballs de sociolingüística catalana $\mathrm{n}^{\circ} 11$, Valencia, Eliseu Climent.

Kremnitz, G. (1981) "Du "bilinguisme" au "conflit linguistique". Cheminement de termes et de concepts ", Langages $\mathrm{n}^{\circ} 61$.

Leprêtre, M., BAÑeres J. (2002) «La sociolinguistique catalane: de la dénomination d'école à l'appellation géographique. Une approche idéelle», Terminogramme ${ }^{\circ}$ 103-104, Montréal, Les Publications du Québec, 105-127. 
Mackey, W. F. (1976) Bilinguisme et contact de langues, Paris, Klincksieck.

Moll, A. (1989) «Llengua i nació», El nacionalismo català a la fi del segle XX, II Jornadas, Barcelona,Edicións de la Magrana/ Edicións 62.

NicolÀs I Amorós, M. (2000) «Linguistes, institutions et locuteurs dans le processus de récupération linguistique: le cas de la langue catalane au XXe siècle», Mémoires de la Société de linguistique de Paris, nouvelle série, Tome VIII, Leuven, Peeters.

Ninyoles, R.- Ll. (1971) Idioma i prejudici, Valencia, Eliseu Climent.

Ninyoles, R.-Ll. (1969) Conflicte Lingûístic Valencià, València, Eliseu Climent Editor.

Ninyoles, R.-Ll. (1976) « Idéologies diglossiques et assimilation ", dans Giordan et Ricard (eds), Diglossie et littérature, Bordeaux-Talence, Maison des Sciences de l'Homme.

Pradilla Cardona, M.-A. (2011) «Introducció», Treballs de sociolingüística catalana, 21, Barcelona, Societat Catalana de Sociolingüística, Institut d'Estudis Catalans, 17-18.

Pradilla Cardona, M.-A. éd. (1999) La llengua catalana al tombant del mil.leni, Barcelona, Editorial Empúries.

Pradilla Cardona, M.-A. (2015) La catalanofonia. Una comunitat del segle XXI a la recerca de la normalitat lingüística, Barcelona, Institut d'Estudis Catalans.

Prats, M. (1989) «Nació i llengua: unas fitas i una reflexió», El nacionalismo català al la fi del segle XX, II Jornadas, Barcelona, Edicións de la Magrana/ Edicións 62.

Pujades, P. (1988) La batalla de la llengua. Converses amb Francesc Ferrer i Gironès, Barcelona, Xarxa Cultural.

Querol, E. COORD. (2007), Llengua $i$ societat als territoris de parla catalana a l'inici del segle XXI, Barcelona, Secretaria de Política Lingüística.

Sendra M., Vila F. X. (2016) “L'estatus de les llengües a la República Catalana: una breu anàlisi del desenvolupament del debat". Els Marges 108, 33-50. 
Sintas, S. (2000), De la « langue baléare » à la (micro)nation baléare, thèse, Université Paul-Valéry, Montpellier III.

Torres i Pla, J. (2011) «La demolingüística en els territoris de llengua catalana» Treballs de sociolingüística catalana, 21, Barcelona, Societat Catalana de Sociolingüística, Institut d'Estudis Catalans, 183-192.

Vallverdú, F. (1980) «Algunes aportacions teóriques dels investigadors catalans a la sociolingüística», Actes del Cinquè Col-loqui Internacional de Llengua i Literatura Catalanes, Andorra, 1-6 d'octubre de 1979, Barcelona, Publicacions de l'Abadia de Montserrat.

Vallverdú, F. (2011) "Historia del col-lectiu GCS/ASOLC/ SOCS", Treballs de sociolingüística catalana, 21, Barcelona, Societat Catalana de Sociolingüística, Institut d'Estudis Catalans, 193204.

Voltas E. (1996) La guerra de la llengua, Barcelona, Empúries. 
